\title{
Wnt-dependent regulation of inner ear morphogenesis is balanced by the opposing and supporting roles of Shh
}

\author{
Martin M. Riccomagno, ${ }^{1,2}$ Shinji Takada, ${ }^{3}$ and Douglas J. Epstein ${ }^{1,4}$ \\ ${ }^{1}$ Department of Genetics, University of Pennsylvania School of Medicine, Philadelphia, Pennsylvania 19104, USA; ${ }^{2}$ Institute \\ of Cell Biology and Neuroscience, University of Buenos Aires School of Medicine, 1121 Buenos Aires, Argentina; ${ }^{3}$ Okazaki \\ Institute for Integrative Biosciences, National Institutes of Natural Sciences Okazaki 444 8787, Japan
}

\begin{abstract}
The inner ear is partitioned along its dorsal/ventral axis into vestibular and auditory organs, respectively. Gene expression studies suggest that this subdivision occurs within the otic vesicle, the tissue from which all inner ear structures are derived. While the specification of ventral otic fates is dependent on Shh secreted from the notochord, the nature of the signal responsible for dorsal otic development has not been described. In this study, we demonstrate that Wnt signaling is active in dorsal regions of the otic vesicle, where it functions to regulate the expression of genes (Dlx5/6 and Gbx2) necessary for vestibular morphogenesis. We further show that the source of Wnt impacting on dorsal otic development emanates from the dorsal hindbrain, and identify Wnt1 and Wnt3a as the specific ligands required for this function. The restriction of Wnt target genes to the dorsal otocyst is also influenced by Shh. Thus, a balance between Wnt and Shh signaling activities is key in distinguishing between vestibular and auditory cell types.
\end{abstract}

[Keywords: Wnt1/3a; Shh; Dlx5; otic vesicle; vestibulum; semicircular canals; hindbrain]

Received February 9, 2005; revised version accepted May 13, 2005.

The vestibular apparatus is the component of the inner ear responsible for sensing balance, motion, and body position. It consists of three semicircular canals and two membranous sacks, the saccule and utricle. Sensory organs housed within each of these structures serve to detect angular and linear acceleration of the head and relay this information along vestibular neurons to vestibular nuclei in the brainstem (Goldberg and Hudspeth 2000). A complex interplay between the vestibular nuclei and axons connecting with the cerebellum, eyes, and spinal cord enables us to maintain balance, stabilize images while in motion, and uphold vertical posture, respectively. Disorders of the inner ear that disrupt the reception or processing of these sensory stimuli result in vertigo, nystagmus, and loss of balance (Sando et al. 2001).

The structural complexity and functional relevance of the vestibular apparatus make it a fascinating model for developmental studies. All mature inner ear structures derive from the otic vesicle, a cyst-like epithelial tissue that forms on either side of the hindbrain (Barald and Kelley 2004). In amniotes, the vestibulum develops primarily from the dorsal otocyst, while the cochlea originates mostly from ventral regions of the otic vesicle. The morphogenesis of the vestibular labyrinth from the dor-

${ }^{4}$ Corresponding author.

E-MAIL epsteind@mail.med.upenn.edu; FAX (215) 573-5892.

Article published online ahead of print. Article and publication date are at http://www.genesdev.org/cgi/doi/10.1101/gad.1303905. sal otocyst is a highly intricate process. The semicircular canals emerge initially as two epithelial protrusions or canal plates. The anterior and posterior semicircular canals are generated from the vertical canal plate, whereas the lateral semicircular canal develops from the horizontal canal plate (Martin and Swanson 1993; Chang et al. 2004a). With the fusion of the opposing walls of the epithelial plates and resorption of the central portion, the three fluid-filled canals are formed.

Although simple in its morphology, the otic vesicle is highly patterned at the level of gene expression. Programming the complex array of genes transcribed in the otic epithelium is heavily influenced by extracellular cues emanating from tissues surrounding the inner ear. The initial phase of ear development in the mouse, the induction of the otic placode, is dependent on sources of Fgf derived from the hindbrain (Fgf3) and periotic mesoderm (Fgf8 and Fgf10) (Alvarez et al. 2003; Wright and Mansour 2003; Ladher et al. 2005). Immediately prior to and concomitant with otic placode formation, the expression of a number of transcription factors ( $\mathrm{Pax} 2, \mathrm{Pax} 8$, $D 1 \times 5, G b x 2, H m x 3)$ is initiated in a broad pattern throughout the otic epithelium, presumably in response to Fgf signaling (Alvarez et al. 2003; Wright and Mansour 2003; Ladher et al. 2005). As the development of the ear progresses to the otocyst stage, the expression domains of these and other genes become confined to particular regions of the epithelium destined to give rise to specific 
inner ear structures (Fekete and $\mathrm{Wu} 2002$ ). This refinement of gene expression within the otic vesicle is also dependent on extrinsic signals derived from neighboring tissues as evidenced by the growing number of mouse mutants exhibiting inner ear phenotypes that result from aberrant gene function in the neural tube and surrounding tissues (Chang et al. 2004a). Previous work by our group and others described a role for Shh in promoting ventral otic fates (Liu et al. 2002; Riccomagno et al. 2002). The importance of notochord-derived Shh signaling in inner ear development was realized by the lack of cochlear duct outgrowth in $S h h^{-/-}$embryos resulting from a failure to properly regulate the expression of a number of genes in the ventral otocyst (Liu et al. 2002; Riccomagno et al. 2002).

In this corollary study, our experiments focused on determining the molecular pathways required to regulate the expression of genes in the dorsal otocyst (Dlx5/6, $H m x 2 / 3, G b x 2)$ whose function is critical for vestibular development. Insight to this problem came from the analysis of embryos carrying the Wnt-responsive Topgal reporter gene, which showed that Wnt signaling was active in dorsal regions of the otic vesicle in a pattern indistinguishable to that of Dlx5. Our studies indicate that $D 1 \times 5 / 6$ and Gbx2 are selective targets of Wnt signaling in the dorsal otocyst. Interestingly, the restriction of these Wnt-responsive genes to the dorsal otic epithelium is also influenced by Shh. We further demonstrate that the source of Wnt impacting on dorsal otic development emanates from the dorsal hindbrain, and identify Wnt1 and Wnt3a as the specific ligands required for this function. Wnt $1^{-1-}$; Wnt $3 a^{-/-}$embryos are completely devoid of vestibular structures and to our surprise also show a severe truncation in the cochlear duct. Using an inducible recombination system to permanently mark Wntresponsive cells in the ear, we determined that the cochlear duct is populated by cells exposed to Wnt signaling at an early stage of otic development. Taken together, our data indicate essential roles for Wntl and Wnt3a in promoting the development of both dorsal (vestibular) and ventral (cochlear) components of the inner ear.

\section{Results}

Wnt/ß-catenin signaling is active in the dorsal otocyst

Members of the Wnt family of secreted glycoproteins have been identified in several tissues that impact on the inner ear (Parr et al. 1993; Barald and Kelley 2004). To determine where and when Wnt signaling is active during early stages of inner ear development, we evaluated embryos carrying the Wnt-responsive Topgal transgene for reporter activity (Fig. 1; DasGupta and Fuchs 1999). At the time of otic placode induction (eight to 10 somites), Topgal staining was detected at the junction between the surface ectoderm and the neural tube consistent with the known site of neural crest formation (Fig. 1a). With the completion of the otic induction phase (12 somites), revealed by the thickening of the surface
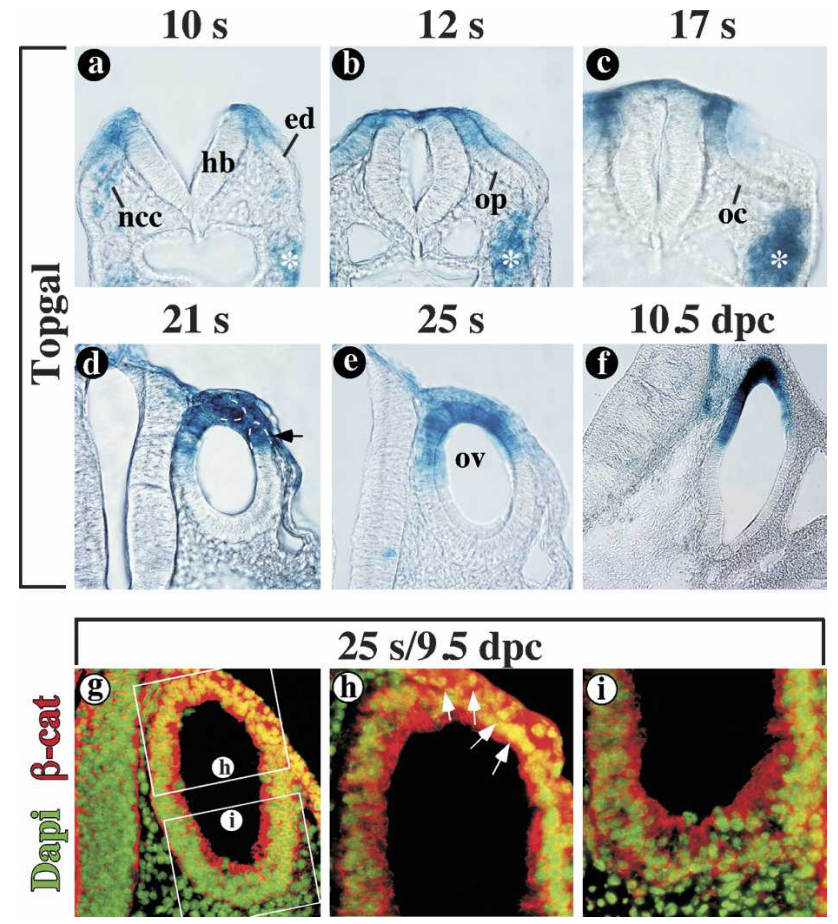

Figure 1. Wnt $/ \beta$-catenin activity within the developing inner ear. $(a-f)$ Transverse sections through the otic epithelium of Topgal embryos stained with X-gal. Topgal expression is restricted to the dorsomedial region of the placode at 10 somites $(10 \mathrm{~s})(a), 12$ somites (12 s) (b), and 17 somites (17 s) (c). Expression of Topgal extends throughout the dorsal otic vesicle at 21 somites $(21 \mathrm{~s})(d), 25$ somites $(25 \mathrm{~s})(e)$, and $10.5 \mathrm{dpc}(f)$. Doted lines in $d$ mark the tips of the lateral and medial walls of the epithelia as they fuse. The black arrowhead points to the expression of Topgal soon after it expands to the lateral side of the otocyst. $(g-i)$ Transverse sections through the otic vesicle of a 25 -somite/9.5-dpc wild-type embryo stained with $\beta$-catenin antibody (red) and Dapi (green). Boxes mark the dorsal and ventral otic regions shown at higher magnification in $h$ and $i$, respectively. White arrows point to representative cells showing nuclear $\beta$-catenin staining. White asterisk marks Topgal staining in the branchial arch. (ed) Ectoderm; (hb) hindbrain; (ncc) neural crest cells; (oc) otic cup; (op) otic placode; (ov) otic vesicle.

ectoderm, Topgal staining was evident in the dorsomedial portion of the otic epithelium in close proximity to the dorsal neural tube (Fig. 1b). Topgal reporter activity retained its dorsomedial localization as the otic epithelium invaginated to form the otic cup (Fig. 1c). Interestingly, when the tips of the lateral and medial walls of the otic epithelium fused at the 21-somite stage, X-gal staining expanded to cover the entire dorsal half of the otic epithelium and remained this way throughout the period of otic vesicle maturation (Fig. 1d-f). Thus, from placode to vesicle stages, Wnt reporter activity was detected in dorsal portions of the developing inner ear.

To confirm that Topgal staining was truly reflective of activated $W n t / \beta$-catenin signaling in the dorsal otic epithelium, the cellular distribution of $\beta$-catenin was examined. In the absence of Wnt signaling the cytoplasmic 
pool of $\beta$-catenin is rapidly degraded, whereas upon Wnt pathway activation $\beta$-catenin is stabilized, is translocated to the nucleus and, in conjunction with Lef/Tcf transcription factors, is responsible for regulating the expression of Wnt target genes (Bienz and Clevers 2003; Cong et al. 2003; Tolwinski and Wieschaus 2004). At 9.5 $\mathrm{d}$ post-coitum (dpc), nuclear $\beta$-catenin was primarily detected in cells of the dorsal otocyst, with little evidence of staining in ventral otic regions (Fig. 1g-i). Given the similarity in expression between nuclear $\beta$-catenin and Topgal, we conclude that the dorsal otocyst is an active site of canonical Wnt signaling. Other required components of the Wnt signaling pathway, including members of the TCF transcription factor and Frizzled receptor families, were also expressed in the otic epithelium between 8.5 and $10.5 \mathrm{dpc}$, in further support of our finding that Wnt signaling is active in the dorsal otocyst (data not shown).

Dlx5 and Topgal expression overlap in the dorsal otocyst and are antagonized by Shh signaling

The homeobox gene Dlx5 is one of several orthologs of Drosophila distal-less (dll) that is expressed in the vertebrate ear (Panganiban and Rubenstein 2002). Initially, Dlx5 covers a broad patch of surface ectoderm encompassing the otic placode (Fig. 2a; Acampora et al. 1999). Over a 24-h period, the expression of Dlx5 becomes localized to the dorsal otocyst (Fig. 2b).

While the patterns of Topgal and Dlx 5 clearly differed at the otic placode stage, they showed very similar expression in dorsal regions of the otic epithelium after $9.25 \mathrm{dpc}$ (Fig. 2a-d). To determine the extent of overlap between Dlx5 and Topgal, double-labeling experiments using $\alpha$-Dlx and $\alpha$ - $\beta$ gal antibodies were performed on otic sections from embryos between 9.5 and $11.5 \mathrm{dpc}$. The $\alpha$-Dlx antibody cross-reacts with several Dlx family members (Panganiban et al. 1995); thus in the otic vesicle, it is expected to recognize both Dlx5 and Dlx6 since the two genes are coregulated in this and other tissues (Robledo et al. 2002). Notably, the expression of Dlx5/6 and Topgal exhibited significant colocalization in the dorsal otocyst of wild-type embryos (Fig. 2e-g,l-n).

We previously reported that Dlx5 expression in the otic vesicle is negatively regulated by Shh (Riccomagno et al. 2002). Since Dlx5/6 and Topgal show a similar distribution in the dorsal otocyst, we postulated that Shh could also be antagonizing Wnt signaling activity in ventral regions of the otic vesicle. To test this hypothesis, Dlx5/6 and Topgal expression were evaluated in Shh loss- and gain-of-function mutants. At $10.5 \mathrm{dpc}$, both Dlx5/6 and Topgal expression showed a significant ventral expansion in $S_{h h^{-/}}$embryos compared with wildtype littermates, resulting in a $33 \%$ increase $(p<0.01)$ in the number of Dlx5/ $6^{+}$; Topgal ${ }^{+}$cells (Fig. 2e-j). At this stage, proliferation rates in $S h^{-/-}$otic vesicles are equivalent to wild type, suggesting that the observed ventral expansion is not due to preferential proliferation of dorsal otic cells (Riccomagno et al. 2002). In keeping with this result, the dorsal otic staining of Dlx5/6 and

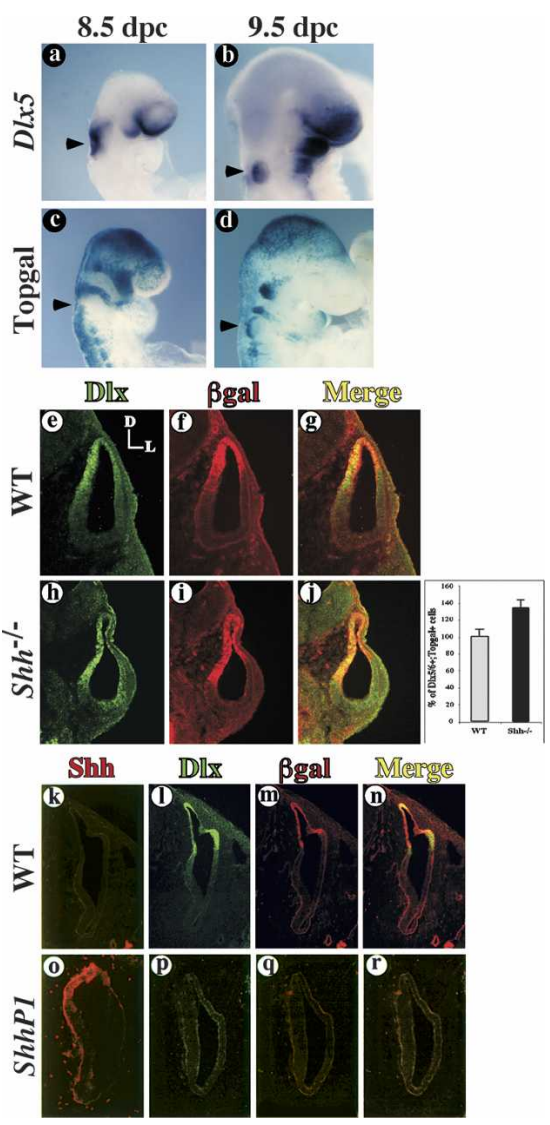

Figure 2. Topgal and Dlx5 colocalize in the dorsal otocyst and are antagonized by Shh. Whole-mount staining for Dlx 5 mRNA $(a, b)$ and Topgal expression $(c, d)$ at $8.5 \mathrm{dpc}(a, c)$ and $9.5 \mathrm{dpc}(b, d)$. Black arrowheads point to the otic epithelium. $(e-r)$ Transverse sections through Topgal $(e-g, k-n), S h h^{-1-}$; Topgal $(h-j)$, and ShhP1; Topgal $(o-r)$ embryos at $10.5 \mathrm{dpc}(e-j)$ and $11.5 \mathrm{dpc}(k-r)$. Antibody staining for Dlx is in green $(e, h, l, p), \beta$-galactosidase in red $(f, i, m, q)$, and merged channels in yellow $(g, i, n, r)$. Note that Shh expression is normally absent in the wild-type otocyst $(k)$ and ectopically expressed in the dorsal region of the ear in ShhP1 embryos $(0)$. The graph shows a $33 \%$ increase in $\mathrm{Dlx}^{+}$; Topgal ${ }^{+}$cells in ShhP1 embryos compared with wild type $(p<0.01$, cell counts were normalized to wild type). (D) Dorsal; (L) lateral.

Topgal was extinguished in ShhP1 embryos, a transgenic line that ectopically expresses $\mathrm{Shh}$ in the dorsal otocyst (Fig. 2k-r; Riccomagno et al. 2002). From these data, we conclude that Shh functions to restrict Dlx5/6 and Wnt signaling activity to the dorsal otocyst.

\section{Lithium induces $W n t / \beta$-catenin responsive genes in the otic vesicle}

The coexpression of Topgal and Dlx5 in the dorsal otocyst, in addition to their concordant responses to modulations in Shh signaling, suggested that Dlx5 is a transcriptional target of the Wnt pathway in the inner ear. As an initial test of this hypothesis, we dissected otic vesicles and their surrounding tissues from embryos at 
$9.25 \mathrm{dpc}$ and cultured them in the presence or absence of lithium chloride ( $\mathrm{LiCl}$ ) for $24 \mathrm{~h}$. $\mathrm{LiCl}$ is known to act as a Wnt/ $\beta$-catenin pathway agonist by inhibiting Gsk3 $\beta$ function, a negative regulator of canonical Wnt signaling (Hedgepeth et al. 1997).

Otic explants carrying the Topgal reporter were used to evaluate the extent of Wnt pathway activation in response to increasing concentrations of $\mathrm{LiCl}$. At the lowest dose tested $(1 \mathrm{mM}), \mathrm{LiCl}$ had no effect on the intensity or spatial distribution of X-gal staining compared with untreated control explants (Fig. 3A, panel a; data not shown). In contrast, otic explants cultured in higher concentrations of $\mathrm{LiCl}$ showed a dramatic ventral expansion of Topgal reporter activity in a dose-dependent manner (Fig. 3A, panels a-f). At the highest doses of $\mathrm{LiCl}$ (40-50 mM), the otic vesicles became dysmorphic, showing a highly thickened epithelium and smaller overall size (Fig. 3A, panels e,f). Therefore, all subsequent experiments were performed using a $30 \mathrm{mM}$ dose of $\mathrm{LiCl}$, the concentration that resulted in maximal Wnt pathway activation without adversely affecting otic vesicle morphology (Fig. 3A, panel d)

Otic explants cultured in the presence of $30 \mathrm{mM} \mathrm{LiCl}$ showed a complete ventral expansion of Dlx5 expression, similar to the pattern of Topgal staining (Fig. 3B, panels a,g). As with Topgal, the degree of ectopic Dlx5 expression correlated with the dose of $\mathrm{LiCl}$ in the culture (data not shown). To address whether other dorsal otic markers were equally responsive to Wnt signaling, we evaluated the expression of $G b x 2, W n t 2 b$, and $H m x 3$. Expression of $G b x 2$, a transcription factor normally found in cells overlapping Dlx5 along the dorsomedial wall of the otocyst, also showed a ventral expansion in response to $\mathrm{LiCl}$ treatment, though limited to the medial side of the vesicle (Fig. 3B, panels b,h). In contrast, the expression of $W n t 2 b$ and $H m x 3$ was unchanged in LiCltreated otic explants (Fig. 3B, panels c, d,i,j). The selective response of dorsal otic markers to $\mathrm{LiCl}$ implies that the ventral expansion observed for some did not come about from the complete dorsalization of the otocyst. Additional support for this conclusion stems from the observation that $\mathrm{LiCl}$ failed to repress the ventral expression of Pax2 and Ngn1 (Fig. 3B, panels e,f,k,1). In summary, forced activation of the Wnt $/ \beta$-catenin pathway is sufficient to induce the ectopic expression of some (Dlx5, $G b \times 2)$ but not all (Wnt2b, Hmx3) dorsal otic genes.

\section{Wnt target gene expression in the dorsal otocyst is dependent on signals from the dorsal neural tube}

The finding that transcriptional targets of the Wnt/ $\beta$ catenin pathway were activated in the dorsal region of the otic vesicle raised the question of which tissue was serving as the source of Wnt. Previous studies implicated the hindbrain as a source of secreted factors impacting on various aspects of inner ear development (Mansour et al. 1993; Giraldez 1998; Ladher et al. 2000; Niederreither et al. 2000; Pasqualetti et al. 2001). We thus reasoned that the dorsal hindbrain might also be expressing the Wnt ligand regulating gene transcription in the dorsal otocyst. To test the dependency of the otic vesicle on the dorsal neural tube, otic explants were isolated at 9.25 $\mathrm{dpc}$, cultured in the presence or absence of the dorsal hindbrain for $24 \mathrm{~h}$, and evaluated for the expression of dorsal otic markers (Fig. 4a-c). If a Wnt ligand secreted from the dorsal neural tube is required for Wnt $/ \beta$-catenin pathway activation in the dorsal otocyst, then dorsal hindbrain removal should result in a down-regulation of Topgal reporter activity as well as other Wnt-responsive genes. Moreover, if a Wnt signal is the only factor in the dorsal neural tube necessary for target gene expression in the dorsal otocyst, then $\mathrm{LiCl}$ should be able to substitute for the dorsal hindbrain in maintaining the dorsal otic expression of Wnt-responsive genes. Alternatively, if dorsal neural tube removal has no effect on the expression of Wnt target genes in the dorsal otocyst, then other tissue sources must be implicated. Since the ectoderm overlying the dorsal surface of the otic vesicle is also a
A

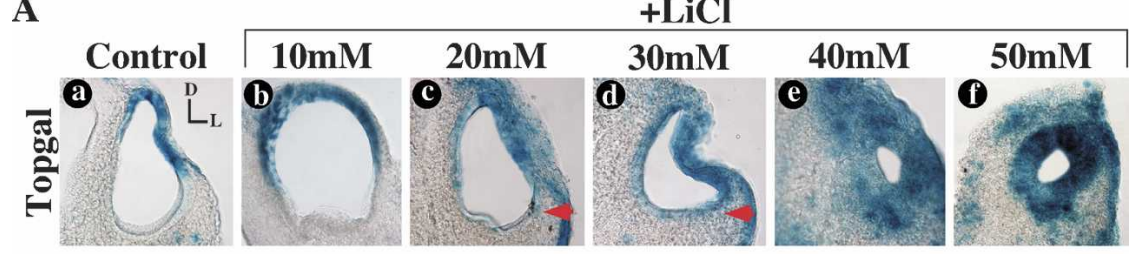

B

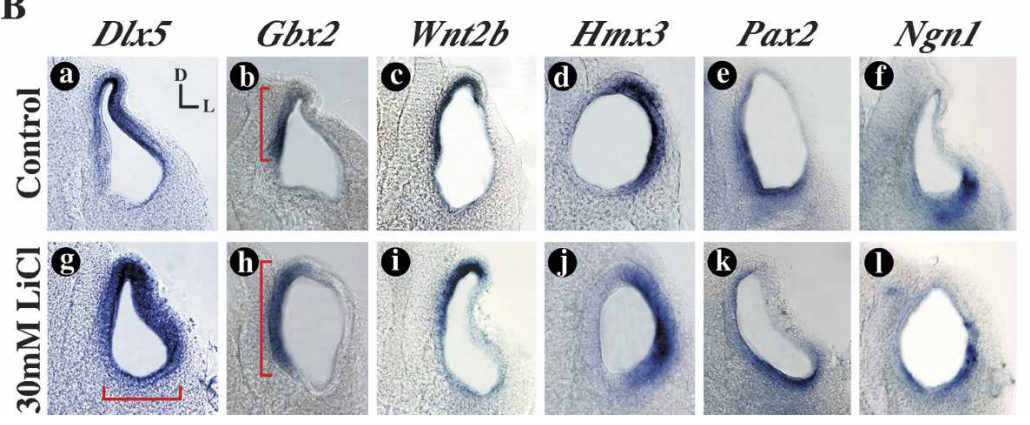

Figure 3. Forced activation of the Wnt/ $\beta$-catenin pathway by $\mathrm{LiCl}$ causes a ventral expansion of Wnt-responsive genes in the otic vesicle. (A) Transverse sections through otic explants stained for Topgal after being cultured for $24 \mathrm{~h}$ in the presence (panels $b-f$ ) or absence (panel $a$ ) of increasing concentrations of LiCl. Red arrowheads point to the expanded domain of Topgal in response to LiCl. $(B)$ Gene expression analysis of otic explants cultured alone (panels $a-f$ ) or in the presence of 30 $\mathrm{mM} \mathrm{LiCl}$ (panels $g-1)$. The red brackets in panels $g$ and $h$ highlight the ectopic expression of Dlx5 and Gbx2, respectively. (D) Dorsal; (L) lateral. 

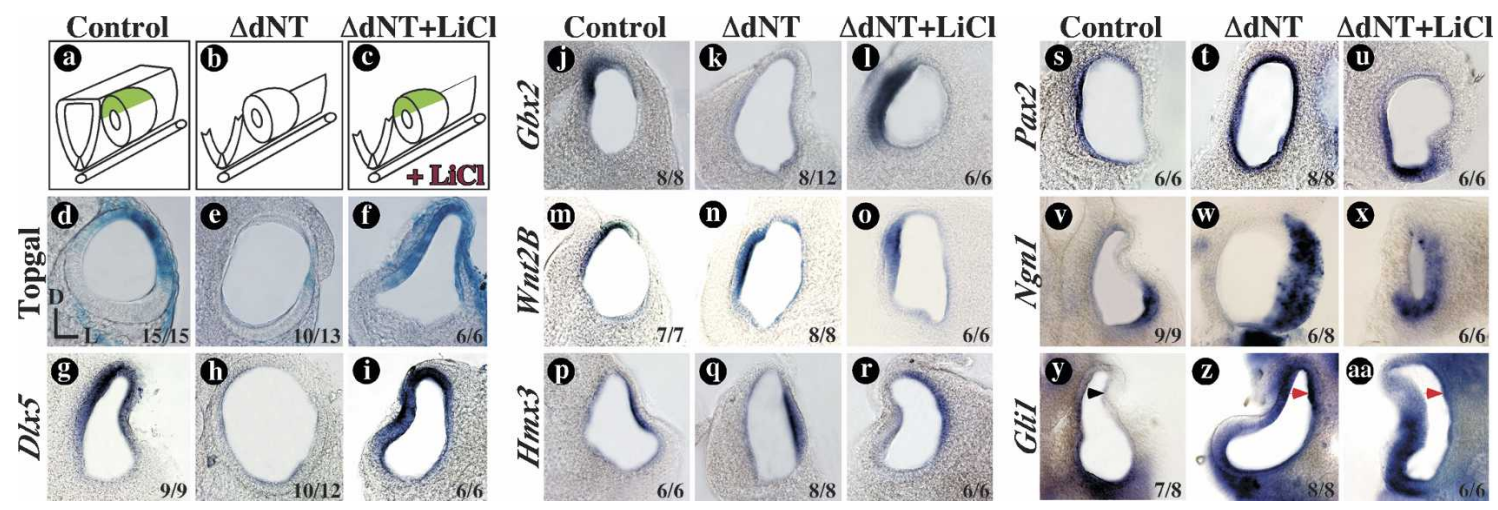

Figure 4. The dorsal neural tube is required for the expression of Wnt-responsive genes and the repression of Shh target genes in the dorsal otocyst. $(a-c)$ Schematic representation of the manipulations performed on otic explants: untreated control explants $(a)$, dorsal neural tube ablated explants $(\Delta \mathrm{dNT})(b)$, and dorsal neural tube ablated explants $(c)$ cultured in the presence of $30 \mathrm{mM} \mathrm{LiCl}$. (d-aa) Gene expression studies on otic explants cultured according to the conditions outlined in $a-c$. The numbers in each panel reflect the reproducibility of the expression pattern indicated. Arrowheads in y-aa point to the absence (black) or presence (red) of ectopic Gli1 expression along the lateral wall of the otocyst. (D) Dorsal; (L) lateral.

source of Wnts, careful effort was made to leave this tissue intact.

Explants in which the dorsal hindbrain was removed showed a significant reduction in Topgal reporter activity in the dorsal otocyst compared with control explants (Fig. 4d,e). A similar down-regulation was observed for Dlx5 and Gbx2 (Fig. 4g,h,j,k). Remarkably, the expression of Wnt-responsive genes was fully restored in the otic vesicles of dorsal-hindbrain ablated explants when cultured in the presence of $30 \mathrm{mM} \mathrm{LiCl}$ (Fig. 4f,i,l). It is important to note that the absence of Topgal, Dlx5, and Gbx2 expression did not result from a loss in the number of cells in the dorsal otic epithelium since mitotic and apoptotic rates were comparable in the otic vesicles of dorsal-hindbrain ablated and control explants (data not shown). Furthermore, the dorsal otocyst was not completely dependent on signals from the dorsal neural tube as evidenced by the unaltered expression of Wnt $2 b$ and $H m \times 3$ upon dorsal hindbrain removal in the presence or absence of $\mathrm{LiCl}$ treatment (Fig. $4 \mathrm{~m}-\mathrm{r}$ ). Taken together, these results strongly implicate the dorsal hindbrain as a likely source of a secreted Wnt ligand required for the maintenance of Dlx5 and Gbx2 expression.

Factors in the dorsal neural tube limit the expression of Shh-dependent target genes in the otic vesicle

Prompted by our earlier observations that Shh signaling is necessary and sufficient to restrict the expression of certain dorsal otic genes (Fig. 2), we set out to determine whether the reciprocal is also true; that is, are targets of Shh signaling in the otic vesicle antagonized by signals from the dorsal neural tube. Pax2 and Ngn1 are Shhdependent genes required for cochlear and cochlear-vestibular ganglia formation, respectively (Riccomagno et al. 2002). The expression of both Pax2 and Ngn1 was expanded ectopically along the lateral wall of the otocyst in explants lacking the dorsal hindbrain (Fig. 4s,t,v,w).
To confirm that the misexpression of Pax2 and Ngn1 resulted from an expansion of the Shh-responsive field within the otic epithelium, we analyzed the expression of Gli1, a molecular readout of Shh signaling. As with Pax2 and Ngn1, the lateral portion of the otic epithelium, an area that does not normally respond to Shh signaling, displayed heightened activation of Gli1 transcription (Fig. $4 y, z)$. Interestingly, treatment of dorsal hindbrain ablated explants with $30 \mathrm{mM} \mathrm{LiCl}$ did not fully restore the expression of Shh target genes to their normal level and position (Fig. $4 \mathrm{u}, \mathrm{x}, \mathrm{aa}$ ). The observation that Shh signaling is dorsally expanded in the otic vesicles of hindbrain ablated explants may explain why the ectopic expression of Topgal and Dlx5 in response to $\mathrm{LiCl}$ treatment is not as broad under these conditions compared with when the hindbrain is left intact (cf. Figs. 4f,i and 3A [panel d], B [panel g]). These results suggest that cues provided by the dorsal hindbrain restrict Shh signaling to ventral and medial regions of the otic epithelium. It is unlikely, however, that Wnt is the only dorsal hindbrain signal involved in this process since lithium treatment was unable to reduce the ectopic expression of Gli1 and could only partially restore the expression of Pax2 and Ngn1.

\section{Wnt 1 and Wnt3a cooperate to maintain Dlx5/6 and $\mathrm{Gbx} 2$ expression}

Results from the otic explant experiments suggested that the dorsal otocyst is a target of a Wnt ligand derived from the dorsal neural tube. A number of Wnt genes are expressed in the dorsal hindbrain (Parr et al. 1993). Our attention was drawn to Wnt1 and Wnt3a because their expression was present in the roof of the hindbrain and absent from the inner ear at otic vesicle stages (Parr et al. 1993; data not shown). Moreover, the combined activities of Wnt1 and Wnt3a were previously shown to be required for the proliferation and specification of distinct 
cell types in axial and paraxial tissues (Ikeya et al. 1997; Ikeya and Takada 1998; Muroyama et al. 2002). This raised the question of whether Wnt1 and/or Wnt3a could be acting in a similar capacity in the otocyst to regulate $D 1 \times 5$ transcription. Whereas Dlx5 was detected in the otic vesicles of $\mathrm{Wnt1}^{-/-}$and $\mathrm{Wnt} 3 \mathrm{a}^{-/-}$single mutants in a manner indistinguishable from wild-type littermates, its expression was markedly reduced in $\mathrm{Wnt1^{-/- }}$; Wnt $3 a^{-/-}$double mutants at $10.5 \mathrm{dpc}$ (Fig. 5a-d). This result was confirmed by the failure to detect $\alpha$-Dlx antibody staining in $W n t 1^{-1-}$; Wnt $3 a^{-1-}$ embryos, indicating that both Dlx5 and Dlx6 were absent in these mutants (Fig. 5q-s). Expression of $G b \times 2$, the other gene that was responsive to Wnt activity in otic explant culture, also failed to be maintained in $\mathrm{Wnt}^{1^{-1}}$; Wnt $3 \mathrm{a}^{-{ }_{-}^{-}}$otic vesicles (Fig. 5v).

Interestingly, the expression of $\mathrm{Hmx}_{3}$ and $\mathrm{Bmp} 4$, which show considerable overlap with Dlx5 in dorsolateral regions of the wild-type otocyst at $10.5 \mathrm{dpc}$, persisted in the ears of $W n t 1^{-/-}$; Wnt $3 a^{-/-}$double mutant embryos, albeit in a partially compromised manner (Fig. $5 \mathrm{e}-1)$. This suggests that in $W n t 1^{-1-}$; Wnt $3 a^{-1-}$ embryos there is a preferential loss of $D 1 \times 5 / 6$ and $G b x 2$ expression rather than a uniform loss of dorsal otic cells, consistent with the results from otic explant experiments in which the dorsal hindbrain was removed (Fig. 4). The significant reduction in the distance between the anterior and posterior domains of Bmp4 expression in $\mathrm{Wnt1}^{-/-}$; $W n t 3 a^{-/-}$embryos is likely due to the reduction in otic vesicle size exhibited by these mutants (Fig. $5 \mathrm{~m}-\mathrm{p}$ ). Since a progressive reduction in the size of the oto-

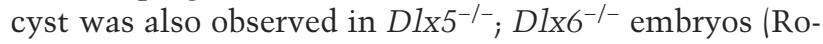
bledo et al. 2002), the small ear phenotype displayed by $W n t 1^{-1-}$; Wnt $3 a^{-1-}$ embryos may be attributed to the failure to maintain $D 1 \times 5 / 6$ transcription.

Given that dorsal neural tube removal resulted in an expanded domain of Shh target gene activation in otic explants, we also wanted to determine whether the same was true in $W n t 1^{-/-}$; Wnt3a $a^{-/-}$embryos. Pax2 and Otx2, two Shh-dependent genes expressed in medial and ventral portions of the otic epithelium, respectively, retained their normal distribution in $W n t 1^{-1-} ; W_{n t 3} a^{-/-}$ embryos (Fig. 5w-bb). These findings are in agreement with the data from otic explants and argue that the restriction of Shh signaling to primarily ventral and medial regions of the otocyst is controlled by hindbrain signals other than Wnt1/3a.

\section{Wnt 1 and Wnt3a are required for inner ear morphogenesis}

We next examined the morphology of the inner ears of Wnt1 $1^{-1-}$; Wnt $3 a^{-/-}$embryos by the paint-fill technique (Martin and Swanson 1993). At the gross anatomical level, inner ear morphogenesis appeared normal in each of the $W n t 1^{-/-}$and $W n t 3 a^{-/}$single mutants at $14.5 \mathrm{dpc}$ (Fig. 6a-c). In marked contrast, the inner ears from Wnt1 $1^{-1-}$; Wnt $3 a^{-/-}$double mutant embryos were so severely disrupted that no vestibular components could be identified (Fig. 6d). All that remained was a truncated cochlear-like structure. The absence of vestibular development in Wnt1 $1^{-/}$; Wnt $3 a^{-/-}$embryos is likely due to the down-regulation of $D 1 \times 5 / 6$ and $G b \times 2$ within the otic vesicle since overlapping phenotypes are apparent in embryos carrying mutations in these genes (Robledo et al. 2002; Lin et al. 2005).

\section{Otic progenitors contributing to both vestibular and auditory structures are exposed to Wnt signals at early stages of inner ear development}

The finding that dorsal otic derivatives were disrupted in Wnt1 $1^{-1-}$; Wnt $3 a^{-/-}$embryos is in keeping with our data showing that Wnt signaling activity is restricted to the dorsal otocyst, from where the vestibulum develops. However, the discovery that ventral otic structures were also affected in $W n t 1^{-I-}$; Wnt3a $a^{-/-}$embryos was more of

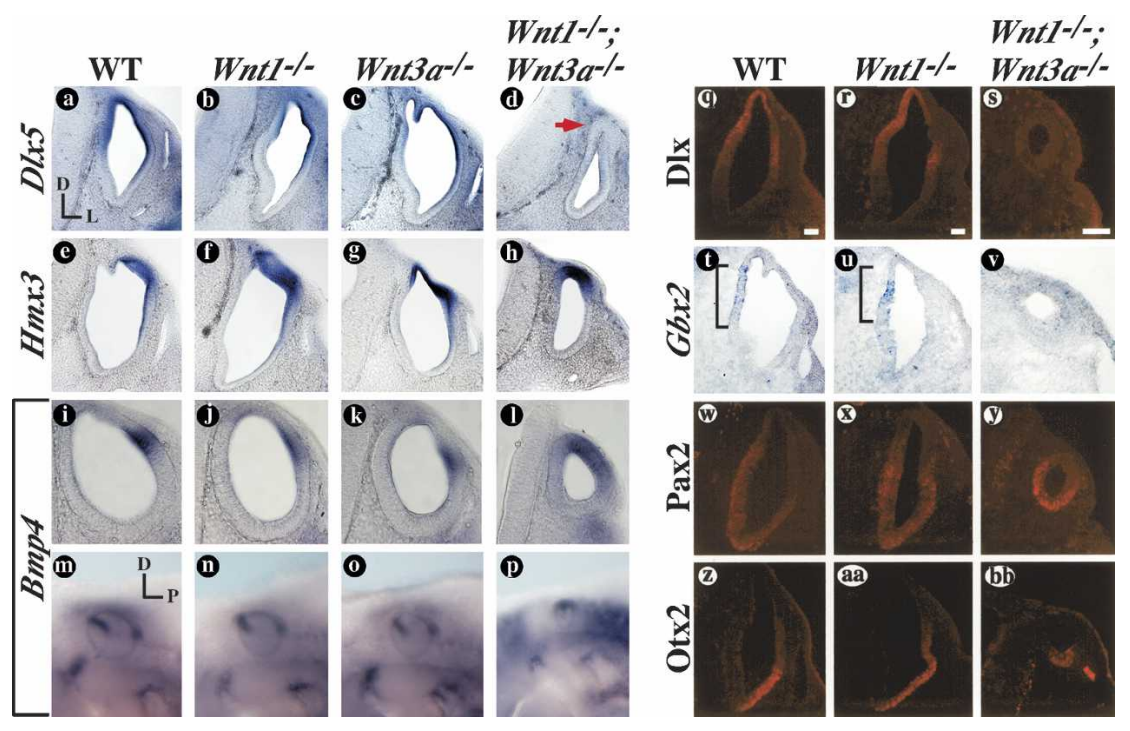

Figure 5. Wnt1 and Wnt $3 a$ are required for the expression of Dlx5/6 and Gbx2 in the otic vesicle at $10.5 \mathrm{dpc}$. Transverse sections $(a-1, q-b b)$ or lateral whole-mount views $(m-p)$ of otic vesicles from wild-type (WT) $(a, e, i, m, q, t, w, z), W n t 1^{-1-}(b, f, i, n, r, u$, $x, a a), W n t 3 a^{-/-}(c, g, k, o)$, and Wnt1 ${ }^{-l-}$; Wnt $3 a^{-1-}(d, h, l, p, s, v, y, b b)$ embryos analyzed by RNA in situ hybridization $(a-p, t-$ $v)$ or antibody staining $(q-s, w-b b)$ for the indicated markers. Red arrow in $d$ highlights the loss of Dlx5 expression. The expression domain of $G b \times 2$, marked by brackets $(t, u)$, is lost in $W n t 1^{-/-}$;Wnt $3 a^{-/-}$ embryos $(v)$. Images in $s, v, y$, and $b b$ are magnified for better display of the expression patterns. The size ratio relative to wild type was unaltered for all other images. Bar, $50 \mu \mathrm{m}$. (D) Dorsal; (P) posterior; (L) lateral. 
Figure 6. Wnt1 $1^{-1-}$; Wnt $3 a^{-/-}$embryos show aberrant inner ear morphology. Analysis of inner ears injected with latex paint from wild type $(a), W n t 1^{-1-}(b)$, Wnt $3 a^{-/-}(c)$, and $W n t 1^{-/-}$; Wnt $3 a^{-/-}(d)$ embryos at 14.5 dpc. (aa) Anterior ampulla; (asc) anterior semicircular canal; (cc) common crus; (cd) cochlear duct; (cls) cochlear-like structure; (ed) endolymphatic duct; (la) lateral ampulla; (lsc) lateral semicircular canal; (pa) posterior ampulla; (psc) posterior semicircular canal; (s) saccule; (u) utricle.
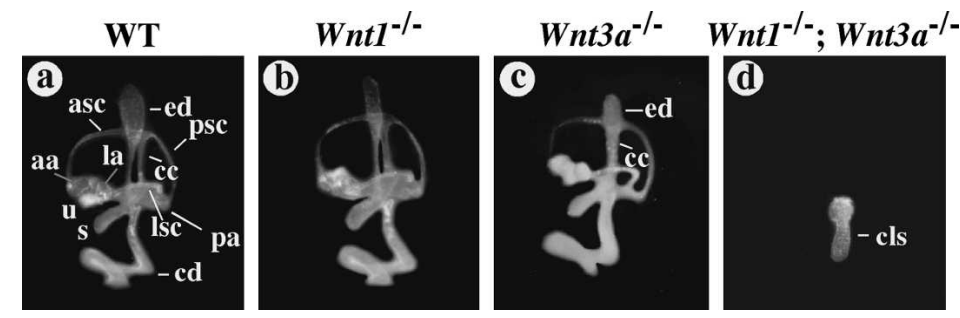

a surprise, especially since ventral otic determinants were appropriately expressed in these mutants (Fig. 5wbb). A number of possible explanations can account for

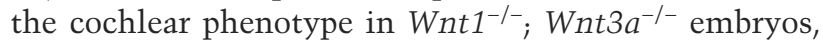
including cell-autonomous and nonautonomous functions of Wnt target genes. Unfortunately, definitive roles for Dlx5/6 and Gbx2 in cochlear development have not been reported (see Discussion). Our efforts to address this problem focused on determining the fate of Wntresponsive cells at early stages of otic development. As an approach, we made use of the tamoxifen-inducible recombination system by generating a transgenic mouse line carrying the Cre-ERT2 fusion gene downstream of the Wnt-responsive Top promoter (TopCreERT2) (DasGupta and Fuchs 1999; Indra et al. 1999). The overall pattern of TopCreERT2 mRNA expression in embryos was very similar to that of Topgal, suggesting that this transgene is responsive to Wnt signaling (data not shown). With respect to the inner ear, TopCreERT2 mRNA expression was confined to dorsomedial cells of the otic cup at $8.5 \mathrm{dpc}$ and dorsal cells of the otic vesicle between 9.5 and $10.5 \mathrm{dpc}$, in a manner highly reminiscent of Topgal (Fig. 7a,b).

Crossing TopCreERT2 males with females homozygous for the $R 26 R$ reporter allele and administering tamoxifen at specific time points during gestation achieved permanent labeling of Wnt-responsive cells. For these experiments we attempted to initiate reporter activity at or around the time of otic cup closure by administering tamoxifen between 8.5 and $8.75 \mathrm{dpc}$. The fate of these labeled cells was surveyed between 9.5 and 14.5 dpc. Remarkably, when examined at $9.5 \mathrm{dpc}$, X-gal staining was not simply detected in the dorsal otocyst, as was predicted by the pattern of TopCreERT2 mRNA and Topgal expression, but included cells along most of the medial wall of the vesicle (Fig. 7c). Control mice of the same genotype fed mineral oil showed no evidence of reporter activity in the inner ear (data not shown). As inner ear morphogenesis progressed between 10.5 and $12.5 \mathrm{dpc}, \mathrm{lacZ}^{+}$cells continued to occupy the medial wall of the otic epithelium, including the outgrowing endolymphatic and cochlear ducts (Fig. $7 d_{\text {; }}$ data not shown). When examined between 13.5 and $14.5 \mathrm{dpc}_{\text {, lacZ }}{ }^{+}$cells were observed throughout the utricle, common crus, endolymphatic duct, and the anterior and posterior semicircular canals, including their corresponding ampullae (Fig. 7e,f; data not shown). Very little X-gal staining was detected in the lateral canal likely due to the limited number of lac $\mathrm{Z}^{+}$cells on the dorsolateral side of the oto- cyst (Fig. 7d-f). Interestingly, X-gal staining detected along the length of the cochlea and saccule was restricted to the sensory (medial) side of the epithelium (Fig. $7 \mathrm{~g}$ ). These results indicate that Wnt-responsive cells in the dorsomedial portion of the otic cup contribute not only to a variety of dorsally derived inner ear structures but also, unexpectedly, to ventral otic derivatives including the cochlea and saccule. Prohibiting the exposure of cells in the dorsomedial region of the otic cup to Wnt1 and Wnt3a may be the cause of the cochlear phenotype observed in $W_{n t 1^{-/-}}$; Wnt3a $a^{-/-}$embryos.

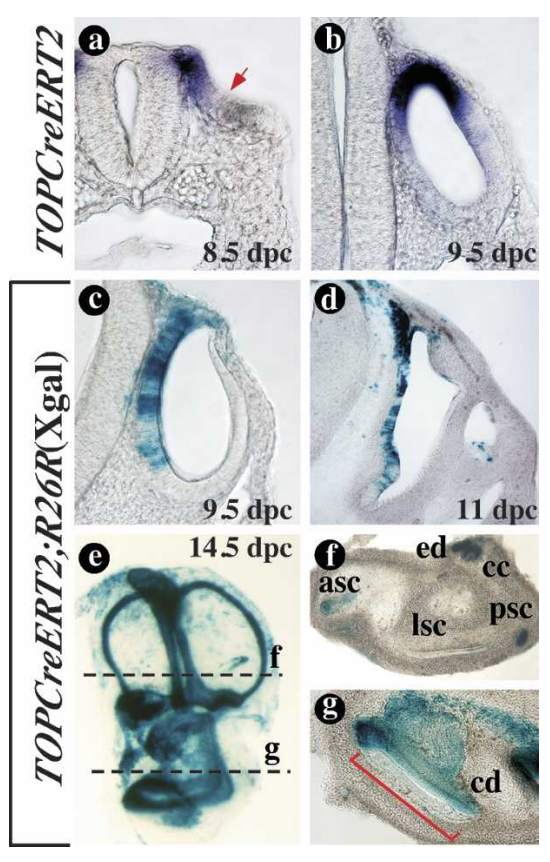

Figure 7. Fate mapping of Wnt-responsive cells in the inner ear. $(a, b)$ TopCreERT2 expression in the inner ear was revealed by RNA in situ hybridization. Red arrow points to the ventral hinge point of the otic cup. $(c-g) \mathrm{X}$-gal staining of inner ears from TopCreERT2; R26R/+ embryos administered with tamoxifen at $8.75 \mathrm{dpc}$. Cells that have responded to Wnt signaling are located along most of the medial and dorsal regions of the vesicle at $9.5 \mathrm{dpc}(c)$ and $11.0 \mathrm{dpc}(d)$. (e) Whole-mount view of the inner ear at $14.5 \mathrm{dpc} .(f, g)$ Transverse sections through the ear shown in $e$ revealing the contribution of Wnt-responsive cells to the vestibule $(f)$ and medial wall of the cochlea $(g)$. Red bracket marks the unstained lateral wall of the cochlea. (asc) Anterior semicircular canal; (cc) common crus; (cd) cochlear duct; (ed) endolymphatic duct; (lsc) lateral semicircular canal; (psc) posterior semicircular canal. 


\section{Discussion}

Wnt signaling form the dorsal neural tube is required for dorsal otic patterning

Extracellular signaling molecules provide the inner ear with positional information at multiple stages of its development to produce the required patterns of growth and differentiation necessary for the formation of the vestibulum and the cochlea, the two inner ear organs responsible for sensing balance and sound, respectively (Barald and Kelley 2004). Experiments performed in the present study set out to address the nature and source of the signaling molecules required to impart dorsal (vestibular) identity within the otic vesicle.

Our data show that the inner ear is a direct target of Wnt signaling as early as the otic placode stage. Cells in the dorsomedial region of the placode were positive for the Wnt-responsive Topgal reporter. At these early stages a number of Wnt ligands, including Wnt1 and Wnt3a, are expressed in the dorsal neural tube immediately adjacent to the portion of the placode responsive to Wnt signaling (Parr et al. 1993; data not shown). By 9.5 dpc, the dorsal cells of the otic vesicle that remain closest to the source of Wnts in the dorsal neural tube continue to express the Topgal reporter gene. The distance between the dorsal otocyst and the source of Wnt1 and Wnt3a in the dorsal midline of the neural tube at $9.5 \mathrm{dpc}$ is well within the range of signaling $(100 \mu \mathrm{m})$ proposed for these ligands in the spinal cord (Megason and McMahon 2002). The best evidence in support of a direct action of dorsal neural tube Wnt signals on the dorsal otocyst was obtained in explant experiments, which revealed that Topgal expression in the dorsal otocyst was fully dependent on the presence of the dorsal neural tube and that $\mathrm{LiCl}$, a Wnt agonist, could substitute for the dorsal neural tube in maintaining Topgal activity in the ear. Interestingly, the dorsal otic expression of Topgal persists after $10.5 \mathrm{dpc}$, an age when the distance between the dorsal neural tube and ear far exceeds the limits of Wnt signaling. Local sources of Wnt signals within the ear have been described that function at these later stages to specify vestibular hair cells (Stevens et al. 2003).

Loss of Dlx5/6 and Gbx2 account for the vestibular defects in $\mathrm{Wnt}^{-/-}$; Wnt3a $\mathrm{a}^{-/}$embryos

Several lines of evidence indicate that the expression of $D 1 \times 5 / 6$ and $G b x 2$ in the dorsal otocyst is dependent on Wnt signaling. The expression of Dlx5 and Gbx2 was expanded in otic explants treated with $\mathrm{LiCl}$ and lost in otic explants in which the dorsal hindbrain was removed. Importantly, $\mathrm{LiCl}$ was sufficient to restore Dlx5 and Gbx2 expression in dorsal hindbrain ablated explants, arguing that the only dorsal neural tube signal required to maintain the expression of these genes belongs to the Wnt family (Fig. 8). In support of this claim, the expression of $D 1 \times 5 / 6$ and $G b \times 2$ was lost from the dorsal otocyst of $\mathrm{Wnt1}^{-/-}$; Wnt3a $\mathrm{a}^{-/-}$embryos at $10.5 \mathrm{dpc}$. The early expression of these genes throughout the otic

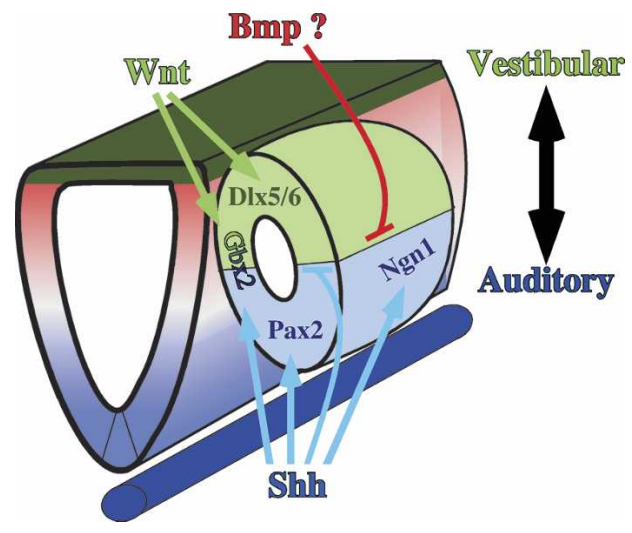

Figure 8. Model depicting how inner ear polarity is generated in response to extracellular signals. Wnt signals secreted by the dorsal neural tube (dark green) are necessary and sufficient for the regulation of Dlx5/6 in the dorsal otocyst (light green). This contrasts with the function of Shh emanating from the notochord (blue), which specifies ventral otic cell fates by regulating the transcription of genes, including Pax2 and Ngn1 (light blue). The combination of Wnt and Shh signaling activities are required for the maintenance of $G b \times 2$ along the dorsomedial side of the otocyst (green-blue shading). Shh also restricts Wnt pathway activation, and consequently Dlx5/6 expression, to dorsal regions of the otic vesicle. An additional signal secreted from the dorsal neural tube, possibly a Bmp family member (red), restricts Shh target genes to the ventromedial domain of the otocyst. A balance between these dorsal and ventral signals is key to promoting regional identity within the otic epithelium with the ultimate goal of coordinating the morphogenesis of vestibular and auditory organs.

placode is unlikely to be dependent on Wnt signaling since Topgal and $D 1 \times 5 / G b x 2$ only partially overlap at this stage.

The Wnt-dependent regulation of Dlx5 expression in the mouse ear is remarkably similar to the molecular mechanism underpinning specification of the Drosophila antenna, which, like the vertebrate ear, houses mechanosensory structures responsible for transmitting auditory information to the brain. One of the many functions of $\mathrm{wg}$ (a Wnt1 ortholog) is to direct the expression of dll (a Dlx5 homolog) to the antenna and other tissues (Diaz-Benjumea et al. 1994; Panganiban 2000). Regulating the expression of Dlx5/d1l by Wnt/wg family members may represent part of a conserved pathway used in the specification of sense organs (Panganiban 2000). Interestingly, downstream targets of this regulatory module in the fly antenna are also expressed in the mouse inner ear (for review, see Panganiban and Rubenstein 2002).

The inner ear phenotype exhibited by $D l \times 5^{-/-}$embryos represents a subset of those displayed by $W n t 1^{-/-}$; $W n t 3 a^{-/-}$embryos. While the lack of semicircular canals is a feature common to both mutants, other inner ear structures, including the endolymphatic duct, utricle, saccule, and cochlea, all of which are absent or indistinct in $W n t 1^{-/-}$; Wnt $3 a^{-/-}$embryos, still form to varying degrees in Dlx $5^{-1-}$ mutants (Acampora et al. 1999; Depew et al. 1999; Merlo et al. 2002). As a result, the otic phe- 
notype depicted by $W n t 1^{-/-}$; Wnt $3 a^{-/-}$embryos cannot fully be explained by the loss of Dlx5. Interestingly, embryos carrying mutations in both Dlx 5 and Dlx6 show a more drastic phenotype in several tissues, including the inner ear, compared with $D 1 \times 5^{-/-}$embryos alone (Robledo et al. 2002). Dlx $5^{-1-}$; $D 1 \times 6^{-/-}$mutants display a striking reduction in the overall size of the otocyst at 9.5 $\mathrm{dpc}$ and fail to form any dorsal otic derivatives. Thus, the down-regulated expression of both Dlx5 and Dlx6 that we observed in $W n t 1^{-/-}$; Wnt $3 a^{-/-}$embryos better explains the reduction in otic vesicle size and vestibular defects displayed by these mutants.

It is likely that the down-regulated expression of $G b x 2$ also contributes in some part to the $W n t 1^{-/-} ; W n t 3 a^{-/-}$

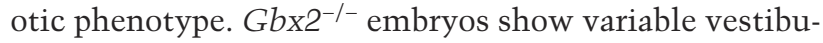
lar malformations that are generally milder than those seen in Wnt1/3a mutants (Lin et al. 2005). This raises the possibility that the inner ear defects in $\mathrm{Wnt1^{-/- }}$; $W n t 3 a^{-/-}$embryos result from the additive effects of losing Gbx2 and Dlx5/6 expression.

\section{Convergence of multiple pathways during vestibular morphogenesis}

While our data indicate that Wnt signaling is necessary and sufficient to maintain the expression of some dorsal otic genes, others including Hmx3 and $W n t 2 b$, were unchanged by dorsal neural tube removal, LiCl treatment, or, in the case of $H m x 3$, targeted disruption of Wnt1 and Wnt3a. Hmx3 and Hmx2 overlap in the dorsolateral region of the otic vesicle and together are required for the development of all vestibular structures (Wang et al. 2004). Similarly, embryos lacking Dlx5 fail to generate semicircular canals (Acampora et al. 1999; Depew et al. 1999; Merlo et al. 2002). The apparent discordance in the mechanisms regulating Dlx5 and $\mathrm{Hm}_{\mathrm{x}}$, coupled with the finding that the expression of each gene is maintained in embryos deficient in the other, supports the notion that two pathways are functioning at early stages of inner ear development to promote the vestibulum (Merlo et al. 2002; Wang et al. 2004). A third pathway operating at a slightly later stage was also shown to promote outgrowth of the semicircular canals (Chang et al. 2004b). In this study, Fgf signaling from the presumptive cristae, the neurosensory tissue located at the base of each semicircular canal, was implicated in canal outgrowth due to its ability to up-regulate Bmp2 in the canal pouch. Bmp family members have previously been implicated in vestibular morphogenesis (Chang et al. 1999; Gerlach et al. 2000). The perturbation of Bmp4 function in the presumptive cristae of chick embryos using the Bmp2/4 antagonist Noggin resulted in a loss of semicircular canal formation. Interestingly, the absence or mislocalized expression of $\mathrm{Bmp} 4$ is a feature common to Wnt1/Wnt3a, Dlx5, and Hmx2/Hmx3 mutants (Fig. 5; Merlo et al. 2002; Wang et al. 2004). For this reason, the three pathways involved in vestibular development described above may be integrating at different levels of a Bmp signaling cascade. In this model, Wnt1/3a-Dlx5 and $\mathrm{Hmx} 2 / 3$ are required to position $B m p 4$ expression within the cristae-forming region of the otic epithelium. This source of Bmp4 would then be involved, either directly or indirectly, in the activation of Fgf (possibly Fgf10) (see Chang et al. 2004b) within the presumptive cristae, which in turn leads to the expression of $B m p 2$ in the canal genesis zone and subsequent outgrowth of the semicircular canals. Future experiments will be needed to confirm the proposed roles of Bmp2 and Bmp4 in vestibular development by the conditional inactivation of these genes in the otic epithelium.

Otic cup cells exposed to Wnt signaling also contribute to the cochlear duct

The spectrum of otic phenotypes observed in $\mathrm{Wnt1^{-/ }}$; $W n t 3 a^{-/-}$mutants exceeds the domains of the otic vesicle that are directly responding to Wnt signaling between 9.5 and $10.5 \mathrm{dpc}$. The failure to maintain $D 1 \times 5 / 6$ and Gbx2 expression in the dorsal otocyst may adequately explain the vestibular defects in $W n t 1^{-/-}$; $W n t 3 a^{-/-}$embryos; however, it remains unclear as to whether the down-regulation of these genes accounts for the hypoplastic cochlea observed in these mutants. A role for Dlx5/6 during cochlear development has yet to be reported. Moreover, only a subset $(26 \%)$ of $G b \times 2^{-/-}$ embryos exhibit cochlear duct malformations, and it is uncertain whether this phenotype results from the loss of a non-cell-autonomous function of Gbx2 in the ear or is the indirect consequence of a hindbrain patterning defect (Lin et al. 2005). Regardless of the potential roles that targets of Wnt signaling may have in cochlear development, our fate mapping studies provide novel insight into the contribution of Wnt-responsive cells to the formation of the cochlear duct. Using an inducible recombination system, we were able to permanently mark Wnt-responsive cells in the otic epithelium prior to closure of the otic cup. Remarkably, many mature inner ear structures stained positively for lacZ activity, including the entire medial side of the cochlear duct and much of the vestibulum. The extent to which the Wnt-responsive cells in the dorsomedial portion of the otic cup contributed to the mature inner ear was not anticipated. Fate mapping studies performed at a similar stage of otic development in the chicken showed that these cells remain exclusively in the dorsal otocyst (Brigande et al. 2000). The expansion of otic epithelial cells that we observed in the mouse is reminiscent of the scattered behavior of otic progenitor cells described in frogs (Kil and Collazo 2001). However, in contrast to this study, we do not know if the broad distribution of Wnt-responsive cells along the medial wall of the mouse otocyst results from cell migration, a rapid expansion of dorsomedial otic progenitors, or both. Regardless of the mechanism, ventral otic progenitors destined to give rise to the cochlear duct are exposed to Wnt signaling at an early stage of inner ear development. The failure to expand this population of cells in $W n t 1^{-/-}$; Wnt $3 a^{-/-}$embryos may explain the limited outgrowth of the cochlear duct observed in these mutants. 
Opposing activities of Shh and Wnt signaling pathways: parallels in somite and inner ear development

Shh specifies ventral fates within the otic epithelium by initiating and/or maintaining the expression of several transcription factors whose function is essential for proper cochlear and cochlear vestibular ganglia formation (Liu et al. 2002; Riccomagno et al. 2002). Our observation that Wnt target genes were expanded ventrally in Shh mutant otocysts revealed an additional function of Shh in ensuring that Wnt signaling remains restricted to the dorsal otocyst (Fig. 8). Six $1^{-/-}$embryos also show a loss of ventral otic targets and a significant ventral expansion of Dlx5 and other dorsally expressed genes, despite possessing normal Shh signaling activity (Zheng et al. 2003; Ozaki et al. 2004). This and additional data suggest that Shh and Six1 are operating in separate pathways to pattern the ventral otocyst and consequently establish a molecular boundary along the dorsoventral axis of the otic vesicle, which delineates the vestibular (dorsal) from auditory (ventral) regions of the inner ear. The molecular boundary that is created by the opposing activities of the Wnt and Shh signaling pathways is not likely to be sharp given that both pathways are required to maintain $G b x 2$ expression on the dorsomedial side of the otocyst (Fig. 8; Riccomagno et al. 2002). This can be justified if $G b \times 2$ expression is dependent on a low concentration of Shh and a high concentration of Wnt. Thus, the balance of Shh and Wnt signaling activities would be key in specifying distinct inner ear fates.

Our data in the ear bear remarkable similarity to the molecular mechanisms underlying the development of another paraxial tissue, the somite. Hh and Wnt signals exhibit opposing and cooperative functions in partitioning the presomitic mesoderm along its dorsoventral axis into dermomyotome (dorsal) and sclerotome (ventral) cell fates (for review, see Brent and Tabin 2002). Wnt signaling promotes the expression of the dermomyotomal marker Pax3 at the expense of the sclerotomal marker Pax1, while Hh signaling mediates the converse function of inducing Pax1 over Pax3 expressing fates (Brent and Tabin 2002). In the mouse, Wnt1 and Wnt3a secreted from the dorsal neural tube are required for the expression of genes in dorsal and dorsomedial regions of the somite (Ikeya and Takada 1998). One target of Wnt1/ 3 a regulation, the myogenic determinant Myf5, is also dependent on Shh signaling, suggesting that Myf5 expression is coordinated by the combination of Shh and Wnt signaling activities (Ikeya and Takada 1998; Borycki et al. 1999; Gustafsson et al. 2002). As with the opposing and cooperative effects of Shh and Wnt in the inner ear, different levels of pathway activation may also dictate the specification of distinct cell fates within the somite.

While Shh is required to restrict Wnt signaling activity to the dorsal otocyst, several lines of evidence suggest that factors other than Wnts are responsible for the reciprocal role of limiting Shh responsiveness to the ventral and medial regions of the inner ear. First, Shh target genes were not expanded dorsally in $W n t 1^{-/-} ; W n t 3 a^{-/-}$ embryos. Second, Shh signaling was not reduced in LiCltreated otic explants despite the ectopic expression of Wnt targets in the ventral otocyst. Third and perhaps of most significance, the dorsal expansion of Shh-responsive genes that resulted from dorsal hindbrain removal in otic explants was not fully restored by $\mathrm{LiCl}$ treatment. We cannot rule out that higher concentrations of $\mathrm{LiCl}$ may be needed to rescue the dorsal otic expansion of Shh target genes however, the $30-\mathrm{mM}$ dose received is likely at or close to saturating levels. Drawing from further comparisons between inner ear and somite development, we propose that Bmp family members expressed in the dorsal hindbrain may be the factors that participate in restricting Shh signaling in the otocyst (Fig. 8). Support for this claim stems from the finding that Noggin, a Bmp2/4 antagonist, is required to prevent Bmp-mediated repression of Shh activity in the ventral somite (McMahon et al. 1998). Formal testing of this hypothesis must await conditional inactivation of Noggin and Bmp family members.

\section{Materials and methods}

Production and genotyping of transgenic mice

The TopCreERT2 construct was generated by replacing the $\beta$-galactosidase cDNA in the Topgal vector (DasGupta and Fuchs 1999) with the CreERT2 fusion gene (Indra et al. 1999). The TopCreERT2 construct was linearized with EcoRI and purified for pronuclear injection by standard methods (Hogan et al. 1994). Genotyping of founder animals using primers for Cre (F, 5'-GCGGCATGGTGCAAGTTGAAT-3'; R, 5' -CGTTCACCG GCATCAACGTTT-3') identified several independent mouse lines carrying the transgene. Evaluation of transgenic lines expressing TopCreERT2 was performed in F1 progeny at various embryonic stages by whole-mount in situ hybridization using a Cre riboprobe. One line showed TopCreERT2 expression in a Wnt-responsive manner similar to the pattern exhibited by Topgal (Fig. 7).

The $W n t 1^{-/-}$; Wnt $3 a^{-/-}$double mutants were identified among embryos derived from matings between compound heterozygotes that were maintained on a C57/B16 background (Ikeya et al. 1997). The $S h h^{+/-}$animals were kindly provided by H. Westphal (National Institutes of Health, Bethesda, MD) (Chiang et al. 1996) and maintained on a CD-1 background (Charles River). The generation of Shh P1 mice has been described previously (Riccomagno et al. 2002). Topgal mice were kindly provided by E. Fuchs (Rockefeller University, New York, NY) (DasGupta and Fuchs 1999). R26R mice were procured from Jackson Laboratories.

\section{Culturing of otic explants}

Otic explants were cultured according to the protocol described in Jeong and Epstein (2003) with slight modifications. Embryos generated from matings between Topgal males and CD-1 females were harvested in ice-cold L15 medium (GIBCO-BRL) at $9.25 \mathrm{dpc}$. Otic vesicles and surrounding tissues, including the periotic mesenchyme, hindbrain, and branchial arches, were explanted from the embryo and cultured on Transwell filters $(0.4$ $\mu \mathrm{m}$, Costar) floating on $47.5 \%$ Dulbecco's minimum essential medium (Specialty Media), 47.5\% F-12 Ham's nutrient mixture (GIBCO-BRL), 2 mM glutamine (GIBCO-BRL), $100 \mathrm{U} / \mathrm{mL}$ penicillin-streptomycin (GIBCO-BRL), and 5\% rat serum (Harlan) in 
the presence or absence of $\mathrm{LiCl}(10-50 \mathrm{mM})$. In some experiments the dorsal neural tube was surgically removed prior to culturing the explant. After $24 \mathrm{~h}$ of culture in a $\mathrm{CO}_{2}$ incubator at $37^{\circ} \mathrm{C}$, explants were fixed and stained with X-gal or processed for whole-mount RNA in situ hybridization. After staining, embryos were post-fixed in $4 \%$ paraformaldehyde, rinsed in PBS, embedded in $4 \%$ agarose, and sectioned on a vibratome at 50-75 $\mu \mathrm{m}$.

\section{Fate mapping and $\beta$-galactosidase staining}

To follow the fate of Wnt-responsive cells, TopCreERT2 males were crossed to R26R/R26R females (Soriano 1999). Cre activity was induced by administering 7-8 $\mathrm{mg}$ of tamoxifen/40 $\mathrm{g}$ of body mass to pregnant females by oral gavage at $8.75 \mathrm{dpc}$.

Whole embryos (9.5-11.5 dpc) or inner ears (14.5 dpc) were dissected in ice cold PBS and fixed in $0.2 \%$ glutaraldehyde/ $1 \%$ formaldehyde wash buffer for $30 \mathrm{~min}$ to $1.5 \mathrm{~h}$ (depending on the stage of development) at $4^{\circ} \mathrm{C}$. Tissues were stained with X-gal solution for $2 \mathrm{~h}$ to overnight (Epstein et al. 2000).

\section{In situ hybridization and paint fill studies}

Whole-mount RNA in situ hybridization was performed essentially as described (Matise et al. 1998) using digoxygenin-UTPlabeled riboprobes. Between two to five embryos of each genotype were analyzed for every probe. Representative embryos were sectioned on a vibratome as described above. Paint fill analysis was conducted according to the method of Martin and Swanson (1993).

\section{Immunohistochemistry}

Antibody staining was performed as previously described (Riccomagno et al. 2002). For detection of $\beta$-catenin, fresh tissue was embedded in OCT and flash-frozen in liquid nitrogen without prior fixation or equilibration. Primary antibodies and dilutions used were as follows: Pax2 (Zymed) 1:250; Dlx (courtesy of J. Kohtz, Northwestern University, Chicago, IL) 1:70; Otx2 (Baas et al. 2000; courtesy of F. Vaccarino, Yale University, New Haven, CT) 1:2000; $\beta$-gal (Promega) 1:200; $\beta$-catenin (Clone 15B8, Sigma) 1:200; Shh (5E1, Developmental Studies Hybridoma Bank) 1:100.

\section{Acknowledgments}

We thank Drs. F. Vaccarino (Yale University) and J. Kohtz (Northwestern University) for $\alpha \mathrm{Otx} 2$ and $\alpha$ Dlx antibodies, Dr. P. Chambon (IGBMC) for the Cre-ERT2 plasmid, and E. Fuchs for the Topgal mouse line. Dr. Jean Richa, the staff at the University of Pennsylvania Transgenic and Mouse Chimeric Facility, and Monika Kumanova are gratefully acknowledged for their assistance in the generation of the TopCreERT2 mouse line. We also thank Drs. Sarah Millar and Jean-Pierre SaintJeannet for helpful comments on the manuscript. Work in D.J.E.'s laboratory is supported by NIH grant DC006254 from NIDCD and a Pew Scholar Award in the Biomedical Sciences.

\section{References}

Acampora, D., Merlo, G.R., Paleari, L., Zerega, B., Postiglione, M.P., Mantero, S., Bober, E., Barbieri, O., Simeone, A., and Levi, G. 1999. Craniofacial, vestibular and bone defects in mice lacking the Distal-less-related gene Dlx5. Development 126: 3795-3809.

Alvarez, Y., Alonso, M.T., Vendrell, V., Zelarayan, L.C., Cha- mero, P., Theil, T., Bosl, M.R., Kato, S., Maconochie, M., Riethmacher, D., et al. 2003. Requirements for FGF3 and FGF10 during inner ear formation. Development 130: 63296338.

Baas, D., Bumsted, K.M., Martinez, J.A., Vaccarino, F.M., Wikler, K.C., and Barnstable, C.J. 2000. The subcellular localization of Otx2 is cell-type specific and developmentally regulated in the mouse retina. Brain Res. Mol. Brain Res. 78: $26-37$.

Barald, K.F. and Kelley, M.W. 2004. From placode to polarization: New tunes in inner ear development. Development 131: 4119-4130.

Bienz, M. and Clevers, H. 2003. Armadillo/ $\beta$-catenin signals in the nucleus-proof beyond a reasonable doubt? Nat. Cell Biol. 5: $179-182$.

Borycki, A.G., Brunk, B., Tajbakhsh, S., Buckingham, M., Chiang, C., and Emerson Jr., C.P. 1999. Sonic hedgehog controls epaxial muscle determination through Myf5 activation. Development 126: 4053-4063.

Brent, A.E. and Tabin, C.J. 2002. Developmental regulation of somite derivatives: Muscle, cartilage and tendon. Curr. Opin. Genet. Dev. 12: 548-557.

Brigande, J.V., Iten, L.E., and Fekete, D.M. 2000. A fate map of chick otic cup closure reveals lineage boundaries in the dorsal otocyst. Dev. Biol. 227: 256-270.

Chang, W., Nunes, F.D., De Jesus-Escobar, J.M., Harland, R., and Wu, D.K. 1999. Ectopic noggin blocks sensory and nonsensory organ morphogenesis in the chicken inner ear. Dev. Biol. 216: 369-381.

Chang, W., Cole, L., Cantos, R., and Wu, D.K. 2004a. Molecular genetics of vestibular organ development. In The vestibular system (eds. S.M. Highstein et al.), pp. 11-56. Springer Verlag, Berlin.

Chang, W., Brigande, J.V., Fekete, D.M., and Wu, D.K. 2004b. The development of semicircular canals in the inner ear: Role of FGFs in sensory cristae. Development 131: 42014211.

Chiang, C., Litingtung, Y., Lee, E., Young, K.E., Corden, J.L., Westphal, H., and Beachy, P.A. 1996. Cyclopia and defective axial patterning in mice lacking Sonic hedgehog gene function. Nature 383: 407-413.

Cong, F., Schweizer, L., Chamorro, M., and Varmus, H. 2003. Requirement for a nuclear function of $\beta$-catenin in Wnt signaling. Mol. Cell. Biol. 23: 8462-8470.

DasGupta, R. and Fuchs, E. 1999. Multiple roles for activated LEF/TCF transcription complexes during hair follicle development and differentiation. Development 126: 4557-4568.

Depew, M.J., Liu, J.K., Long, J.E., Presley, R., Meneses, J.J., Pedersen, R.A., and Rubenstein, J.L. 1999. Dlx5 regulates regional development of the branchial arches and sensory capsules. Development 126: 3831-3846.

Diaz-Benjumea, F.J., Cohen, B., and Cohen, S.M. 1994. Cell interaction between compartments establishes the proximaldistal axis of Drosophila legs. Nature 372: 175-179.

Epstein, D.J., Martinu, L., Michaud, J.L., Losos, K.M., Fan, C., and Joyner, A.L. 2000. Members of the bHLH-PAS family regulate $S h$ transcription in forebrain regions of the mouse CNS. Development 127: 4701-4709.

Fekete, D.M. and Wu, D.K. 2002. Revisiting cell fate specification in the inner ear. Curr. Opin. Neurobiol. 12: 35-42.

Gerlach, L.M., Hutson, M.R., Germiller, J.A., Nguyen-Luu, D., Victor, J.C., and Barald, K.F. 2000. Addition of the BMP4 antagonist, noggin, disrupts avian inner ear development. Development 127: 45-54.

Giraldez, F. 1998. Regionalized organizing activity of the neural tube revealed by the regulation of $\operatorname{lm} x 1$ in the otic vesicle. 
Dev. Biol. 203: 189-200.

Goldberg, M.E. and Hudspeth, A.J. 2000. The vestibular system. In Principles of neural science (eds. E.R. Kandel et al.), pp. 801-816. McGraw-Hill, New York, NY.

Gustafsson, M.K., Pan, H., Pinney, D.F., Liu, Y., Lewandowski, A., Epstein, D.J., and Emerson Jr., C.P. 2002. Myf5 is a direct target of long-range Shh signaling and Gli regulation for muscle specification. Genes \& Dev. 16: 114-126.

Hedgepeth, C.M., Conrad, L.J., Zhang, J., Huang, H.C., Lee, V.M., and Klein, P.S. 1997. Activation of the Wnt signaling pathway: A molecular mechanism for lithium action. Dev. Biol. 185: 82-91.

Hogan, B., Beddington, R., Costantini, F., and Lacy, E. 1994. Manipulating the mouse embryo. Cold Spring Harbor Laboratory Press, Cold Spring Harbor, NY.

Ikeya, M. and Takada, S. 1998. Wnt signaling from the dorsal neural tube is required for the formation of the medial dermomyotome. Development 125: 4969-4976.

Ikeya, M., Lee, S.M., Johnson, J.E., McMahon, A.P., and Takada, S. 1997. Wnt signalling required for expansion of neural crest and CNS progenitors. Nature 389: 966-970.

Indra, A.K., Warot, X., Brocard, J., Bornert, J.M., Xiao, J.H., Chambon, P., and Metzger, D. 1999. Temporally-controlled site-specific mutagenesis in the basal layer of the epidermis: Comparison of the recombinase activity of the tamoxifeninducible Cre-ER(T) and Cre-ER(T2) recombinases. Nucleic Acids Res. 27: 4324-4327.

Jeong, Y. and Epstein, D.J. 2003. Distinct regulators of Shh transcription in the floor plate and notochord indicate separate origins for these tissues in the mouse node. Development 130: 3891-3902.

Kil, S.H. and Collazo, A. 2001. Origins of inner ear sensory organs revealed by fate map and time-lapse analyses. Dev. Biol. 233: 365-379.

Ladher, R.K., Anakwe, K.U., Gurney, A.L., Schoenwolf, G.C., and Francis-West, P.H. 2000. Identification of synergistic signals initiating inner ear development. Science 290: 19651967.

Ladher, R.K., Wright, T.J., Moon, A.M., Mansour, S.L., and Schoenwolf, G.C. 2005. FGF8 initiates inner ear induction in chick and mouse. Genes \& Dev. 19: 603-613.

Lin, Z., Cantos, R., Patente, M., and Wu, D.K. 2005. Gbx2 is required for the morphogenesis of the mouse inner ear: $\mathrm{A}$ downstream candidate of hindbrain signaling. Development 132: 2309-2318.

Liu, W., Li, G., Chien, J.S., Raft, S., Zhang, H., Chiang, C., and Frenz, D.A. 2002. Sonic hedgehog regulates otic capsule chondrogenesis and inner ear development in the mouse embryo. Dev. Biol. 248: 240-250.

Mansour, S.L., Goddard, J.M., and Capecchi, M.R. 1993. Mice homozygous for a targeted disruption of the proto-oncogene int-2 have developmental defects in the tail and inner ear. Development 117: 13-28.

Martin, P. and Swanson, G.J. 1993. Descriptive and experimental analysis of the epithelial remodellings that control semicircular canal formation in the developing mouse inner ear. Dev. Biol. 159: 549-558.

Matise, M.P., Epstein, D.J., Park, H.L., Platt, K.A., and Joyner, A.L. 1998. Gli2 is required for induction of floor plate and adjacent cells, but not most ventral neurons in the mouse central nervous system. Development 125: 2759-2770.

McMahon, J.A., Takada, S., Zimmerman, L.B., Fan, C.M., Harland, R.M., and McMahon, A.P. 1998. Noggin-mediated antagonism of BMP signaling is required for growth and patterning of the neural tube and somite. Genes \& Dev. 12: $1438-1452$.
Megason, S.G. and McMahon, A.P. 2002. A mitogen gradient of dorsal midline Wnts organizes growth in the CNS. Development 129: 2087-2098.

Merlo, G.R., Paleari, L., Mantero, S., Zerega, B., Adamska, M., Rinkwitz, S., Bober, E., and Levi, G. 2002. The Dlx5 homeobox gene is essential for vestibular morphogenesis in the mouse embryo through a BMP4-mediated pathway. Dev. Biol. 248: 157-169.

Muroyama, Y., Fujihara, M., Ikeya, M., Kondoh, H., and Takada, S. 2002. Wnt signaling plays an essential role in neuronal specification of the dorsal spinal cord. Genes \& Dev. 16: $548-553$.

Niederreither, K., Vermot, J., Schuhbaur, B., Chambon, P., and Dolle, P. 2000. Retinoic acid synthesis and hindbrain patterning in the mouse embryo. Development 127: 75-85.

Ozaki, H., Nakamura, K., Funahashi, J., Ikeda, K., Yamada, G., Tokano, H., Okamura, H.O., Kitamura, K., Muto, S., Kotaki, H., et al. 2004. Six1 controls patterning of the mouse otic vesicle. Development 131: 551-562.

Panganiban, G. 2000. Distal-less function during Drosophila appendage and sense organ development. Dev. Dyn. 218: 554 562.

Panganiban, G. and Rubenstein, J.L. 2002. Developmental functions of the Distal-less/Dlx homeobox genes. Development 129: 4371-4386.

Panganiban, G., Sebring, A., Nagy, L., and Carroll, S. 1995. The development of crustacean limbs and the evolution of arthropods. Science 270: 1363-1366.

Parr, B.A., Shea, M.J., Vassileva, G., and McMahon, A.P. 1993. Mouse Wnt genes exhibit discrete domains of expression in the early embryonic CNS and limb buds. Development 119: 247-261.

Pasqualetti, M., Neun, R., Davenne, M., and Rijli, F.M. 2001. Retinoic acid rescues inner ear defects in Hoxa1 deficient mice. Nat. Genet. 29: 34-39.

Riccomagno, M.M., Martinu, L., Mulheisen, M., Wu, D.K., and Epstein, D.J. 2002. Specification of the mammalian cochlea is dependent on Sonic hedgehog. Genes \& Dev. 16: 23652378.

Robledo, R.F., Rajan, L., Li, X., and Lufkin, T. 2002. The Dlx5 and Dlx6 homeobox genes are essential for craniofacial, axial, and appendicular skeletal development. Genes \& Dev. 16: 1089-1101.

Sando, I., Orita, Y., Miura, M., and Balaban, C.D. 2001.Vestibular abnormalities in congenital disorders. Ann. N.Y. Acad. Sci. 942: 15-24.

Soriano, P. 1999. Generalized lacZ expression with the ROSA26 Cre reporter strain. Nat. Genet. 21: 70-71.

Stevens, C.B., Davies, A.L., Battista, S., Lewis, J.H., and Fekete, D.M. 2003. Forced activation of Wnt signaling alters morphogenesis and sensory organ identity in the chicken inner ear. Dev. Biol. 261: 149-164.

Tolwinski, N.S. and Wieschaus, E. 2004. A nuclear function for armadillo/ $\beta$-catenin. PLoS Biol. 2: 486-493.

Wang, W., Grimmer, J.F., Van De Water, T.R., and Lufkin, T. 2004. Hmx2 and Hmx3 homeobox genes direct development of the murine inner ear and hypothalamus and can be functionally replaced by Drosophila Hmx. Dev. Cell. 7: 439-453.

Wright, T.J. and Mansour, S.L. 2003. Fgf3 and Fgf10 are required for mouse otic placode induction. Development 130: 33793390.

Zheng, W., Huang, L., Wei, Z.B., Silvius, D., Tang, B., and Xu, P.X. 2003. The role of Sixl in mammalian auditory system development. Development 130: 3989-4000. 


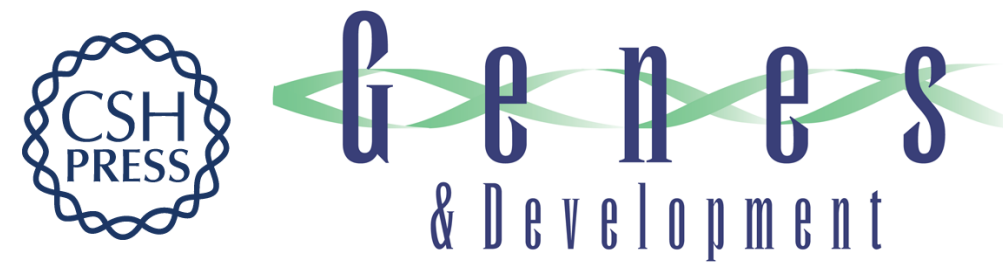

\section{Wnt-dependent regulation of inner ear morphogenesis is balanced by the opposing and supporting roles of Shh}

Martin M. Riccomagno, Shinji Takada and Douglas J. Epstein

Genes Dev. 2005, 19:

Access the most recent version at doi:10.1101/gad.1303905

References This article cites 52 articles, 30 of which can be accessed free at: http://genesdev.cshlp.org/content/19/13/1612.full.html\#ref-list-1

License

Email Alerting

Receive free email alerts when new articles cite this article - sign up in the box at the top Service right corner of the article or click here.

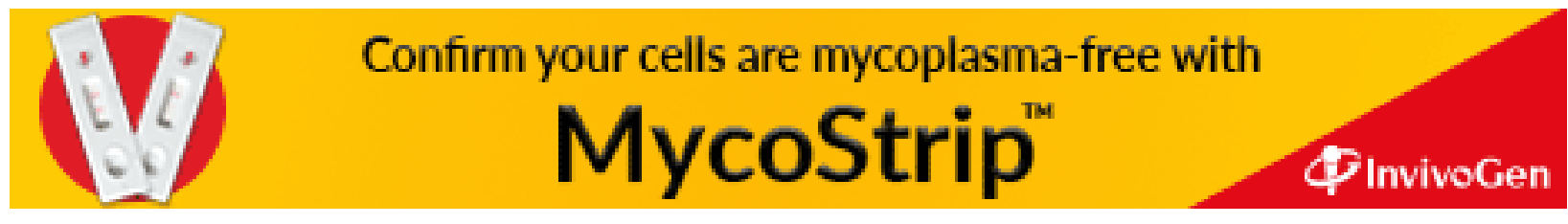

